\title{
La violencia familiar y prácticas de los operadores jurídicos del derecho penal: análisis de cinco casos de Santa Rosa, Argentina
}

Family violence and practices of the legal practitioners of criminal law: analysis of five cases of Santa Rosa, Argentina

Daniela Zaikoski Biscay

\begin{abstract}
Resumen
El artículo analiza la vinculación entre derecho penal y violencia familiar y procura describir y explicar cómo funciona el discurso jurídico y cómo influyen las prácticas judiciales en la aplicación de las leyes de violencia de género
\end{abstract}

Palabras clave: derecho penal - operadores jurídicos - violencia de género - violencia familiar - Argentina.

\begin{abstract}
The article analyzes the link between criminal law and family violence by describing how legal discourses influence the legal practices in the enforcement of gender violence.
\end{abstract}

Key words: criminal law - legal operators - gender violence - family violence - Argentina.

Abogada por la Universidad Nacional de La Plata (UNLP) y especialista en Derecho Público por la Universidad Nacional de Córdoba. Maestranda en Sociología Jurídica de la UNLP; docente de Introducción a la Sociología y Sociología Jurídica en la Universidad Nacional de La Pampa. Es miembro de la Sociedad Argentina de Sociología Jurídica y secretaria judicial en el fuero civil de la provincia de La Pampa, Argentina. Actualmente es investigadora en el proyecto "El discurso de los jueces en las sentencias sobre delitos contra la integridad sexual", aprobado por la Res. N 151/10 del Consejo Académico de la Universidad Nacional de La Pampa, bajo la dirección de la Dra. Olga Salanueva (UNLP). 


\section{INTRODUCCIÓN}

Este artículo se propone abordar la forma en que los operadores jurídicos aplican las leyes contra la violencia hacia las mujeres, más concretamente las de violencia familiar que sufren las mujeres como esposas, novias, concubinas y exconvivientes o no; ejercida por quien es o fue su pareja. Tomaremos como unidades de análisis sentencias dictadas por las Cámaras Criminales de la ciudad de Santa Rosa, en La Pampa, Argentina, en las que se investigaron distintos hechos delictuosos.

Partimos del presupuesto de que los operadores jurídicos trasladan y/o aplican su perspectiva de clase y género al tratamiento de los hechos delictivos en los que les toca intervenir, lo que permitiría afirmar que existe un desfase entre las normas jurídicas y el discurso jurídico de los operadores, que se manifiesta en la persistencia de ciertas prácticas que mantienen al momento de hacer la valoración de los hechos, la selección de las pruebas, el establecimiento de la condena y la graduación de las penas.

Queremos desarrollar y poner en discusión la vinculación de las leyes de violencia de género con las prescripciones del derecho penal. Sostenemos que existe una serie de inconsistencias en el ordenamiento jurídico que dificultan la aplicación efectiva de las leyes de violencia de género en los tribunales penales en Santa Rosa.

Con relación al procedimiento penal y al previsto por la ley nacional № 26.485, creemos que existen ciertas prescripciones contradictorias. Se trata de procesos distintos, se tramitan por separado y provocan ex profeso la escisión de la experiencia de violencia por la que pasan las mujeres.

Consideramos que la respuesta que da el sistema jurídico penal a la problemática de la violencia familiar es insuficiente tanto para la víctima como para el victimario.

Hemos seleccionado un número de fallos que corresponde a las Cámaras Criminales de Santa Rosa (La Pampa) que, aunque pueda resultar exiguo para hacer generalizaciones, nos permite comenzar con el análisis e interpretación del sentido de los usos y las prácticas judiciales, e indagar acerca de lo que la dogmática jurídica ha llamado "la completitud y la neutralidad del fenómeno jurídico".

Sobre la base de los presupuestos antes enunciados y teniendo en cuenta estos postulados, propios del paradigma positivista, perseguimos descubrir que el problema de la violencia familiar es abordado por el discurso y las prácticas de los operadores como un problema jurídico que llega al ámbito judicial, desconociendo la complejidad de la temática; así como también revelar que los operadores jurídicos poseen valoraciones e ideologías que sesgan sus prácticas y decisiones cotidianas, lo que los lleva a "obviar" las cuestiones de género en el derecho penal.

La investigación aquí presentada responde a un carácter cualitativo y de tipo exploratorio, en tanto en nuestro medio no contamos con investigaciones empíricas 
sobre discurso jurídico, violencia familiar y derecho penal. En este sentido, permite hacer una aproximación al objeto de estudio y formular los primeros esquemas conceptuales que presentamos, posibilitando una profundización en la comprensión del sentido que los operadores otorgan a sus prácticas. El trabajo busca identificar variables, precisar los problemas y fundamentalmente permitir a los/las investigadores/ as hallar los procedimientos adecuados para encarar investigaciones posteriores del tipo explicativas. Vale aclarar que el análisis de los cinco casos presentados ${ }^{2}$ no tiene pretensiones de representatividad respecto de la totalidad de la población y los casos penales de Argentina.

Desde el punto de vista metodológico, este tipo de investigaciones permite caracterizar el objeto o unidades de estudio ubicándolos en situaciones concretas y, al contar con un diseño flexible, se facilita el ordenamiento, la agrupación y sistematización de las unidades de análisis mediante criterios de clasificación. En este caso, hemos empezado por las sentencias, cuyos hechos base del análisis fueron muy relevantes por la repercusión social que tuvieron gracias a la militancia de grupos de mujeres y la presencia de ellas en las salas de los juzgados.

\section{GÉNERO Y DERECHO}

La formación de los/as abogados/as en las facultades de derecho de Argentina, quienes luego serán jueces, fiscales o planificadores de políticas públicas, tiene una impronta netamente positivista. El positivismo jurídico alude a una forma de abordar el derecho como orden completo y autorreferente, que regula mediante reglas generales y neutrales las conductas. Este paradigma se caracteriza por individualizar el conflicto social y descontextualizarlo de las luchas que le dan origen. Como forma de construir y aplicar conocimientos en el área jurídica, resulta a todas luces obsoleto para explicar determinados fenómenos, entre ellos, la violencia contra las mujeres y particularmente la violencia familiar, ya que estos problemas refieren a procesos complejos donde se involucran valoraciones acerca del poder, las mujeres y las relaciones interpersonales, y no meramente hechos jurídicos.

Los estudios de género tienen poco que ver con el positivismo jurídico. Mientras el positivismo es el hijo predilecto de la modernidad, el feminismo se ha concentrado en destruir la presunción de igualdad y universalidad que propone la llustración, asumiendo la denuncia del proyecto incompleto de la modernidad (Amoròs, 1990).

Este paradigma supone un saber jurídico naturalizado, dogmatizado y restringido a la letra de la ley. Por el contrario, si se cree que lo jurídico es contingente, producto de luchas sociales, tan inestable y social como cualquier otro conocimiento, entonces

Los casos se seleccionaron a partir de información de la prensa escrita cuando se hicieron los debates orales de las respectivas Cámaras Criminales. A partir de la movilización de mujeres que se hicieron presentes en las salas, los casos tuvieron amplia cobertura mediática y de su lectura se planteó la necesidad de indagar cómo los jueces y otros operadores justifican las elecciones que hacen respecto del tipo penal, las pruebas, las condenas y el monto de las penas. 
sí puede entablarse un diálogo fecundo entre género y derecho para revertir las violencias sociales. Una de ellas es la basada en las diferencias de género.

Sin perjuicio de que hay un sinfín de discusiones acerca del uso y alcances de términos como género y violencia doméstica/familiar/intrafamiliar que se usarán a lo largo del artículo ${ }^{3}$, aquí sostenemos que el género se define por lo relacional, lo histórico y contextual de la situación de hombres y mujeres. Tomaremos la conceptualización de Lamas (2000), quien afirma que:

"las críticas feministas, a pesar de sus diferencias, conceptualizan el género como el conjunto de ideas, representaciones, prácticas y prescripciones sociales que una cultura desarrolla desde la diferencia anatómica entre los sexos para simbolizar y construir socialmente lo que es 'propio' de los hombres (lo masculino) y lo que es 'propio' de las mujeres (lo femenino)" (Lamas, p. 65).

La cultura atribuye cualidades a mujeres y hombres en razón del sexo biológico, derivando desigualdades sociales de las diferencias sexuales. A ellos se les asigna el espacio público y, a ellas, el privado/doméstico. El mundo se descompone en categorías jerarquizadas binarias opuestas: las menos valiosas corresponden a las mujeres, más aún si son pobres, inmigrantes o integrantes de etnias u otros grupos minoritarios. La naturalización de la inferioridad de las mujeres justifica la violencia cometida contra ellas en todas sus formas.

Entenderemos por violencia familiar lo que establece el artículo $6^{\circ}$ de la ley nacional $26485^{4}$ :

\begin{abstract}
"Modalidades: A los efectos de esta ley se entiende por modalidades las formas en que se manifiestan los distintos tipos de violencia contra las mujeres en los diferentes ámbitos, quedando especialmente comprendida las siguientes: a)Violencia doméstica contra las mujeres: aquella ejercida contra mujeres por un integrante del grupo familiar, independientemente del espacio físico donde éstas ocurra, que dañe la dignidad, el bienestar, la integridad física, psicológica, sexual, económica o patrimonial, la libertad, comprendiendo la libertad reproductiva y el derecho al pleno desarrollo de las mujeres. Se entiende por grupo familiar el originado en el parentesco sea por consanguinidad o por afinidad, el matrimonio, las uniones de hecho y las parejas o noviazgos. Incluye las relaciones vigentes o finalizadas, no siendo requisito la convivencia".
\end{abstract}

Es cierto que los problemas de las mujeres no siempre pueden resolverse apelando a leyes y que el derecho produce y reproduce estereotipos sociales, pero es posible que este provea herramientas para generar estrategias emancipadoras. Por eso hay que indagar sobre la relación entre género y derecho.

En cuanto a la problemática, utilidad y alcances de estos conceptos, véase Laurenzo et al., 2008.

$4 \quad$ La ley nacional 26485, denominada "Ley de protección integral para prevenir, sancionar y erradicar la violencia contra las mujeres en los ámbitos en que desarrollen sus relaciones interpersonales", se sancionó en 2009 y fue reglamentada por el decreto 1011/10. En la provincia de La Pampa, en 2010, la legislatura local sancionó la ley 2550 que adhiere a la ley nacional. 
Smart (2000) señala que el derecho tiene género, por lo que no puede presumirse a priori que todo lo que el derecho haga será para explotar a las mujeres y favorecer a los hombres; al mismo tiempo, el derecho es una estrategia creadora de género, es decir, el discurso jurídico crea a la mujer, tal como otros discursos crean al loco, al delincuente, al homosexual.

Si bien el derecho y el discurso positivista de los operadores jurídicos tienen aspiraciones de universalidad e igualdad entre hombres y mujeres, la perspectiva de género denuncia que ello no es así.

\section{LOS MODELOS DEL CÓDIGO PENAL}

Un breve recorrido por las normas del Código Penal de Argentina (CPA) da cuenta que desde la ley se privilegian modelos de mujeres, de hombres y de familias, se crean subjetividades y se dan o niegan derechos. Ruiz (2000) dice: "Cada vez que el derecho consagra alguna acción u omisión como permitida o como prohibida está revelando dónde está el poder y cómo está distribuido en la sociedad" (21).

En esa función -dar, negar y distribuir poder-, el derecho interpela a las mujeres de distintos modos. Según criterios de moralidad, el derecho crea la mujer honesta y quién no lo es, para establecer los tipos penales relacionados con la sexualidad. La lucha de mujeres hizo y sigue haciendo una fuerte crítica para desmontar todo el artefacto jurídico en torno al honor y la moral sexual para que las agresiones sexuales sean tipificadas como delitos contra la integridad o contra la libertad sexual, y que se interprete la norma no en función del sexo, sino del consentimiento de la mujer (Asúa Batarrita, 2008).

Si analizamos otras normas del CPA, constatamos que el derecho penal sustenta un modelo de familia conyugal consanguínea. Así, agrava la pena de homicidio según el vínculo de parentesco que haya entre víctima y victimario. El artículo $80^{\circ}$, inciso $1^{\circ}$, del CPA dice: "Se impondrá reclusión perpetua o prisión perpetua, pudiendo aplicarse lo dispuesto por el art. 52, al que matare: inc. 1\%: a su ascendiente, descendiente o cónyuge, sabiendo que lo son". El derecho privilegia un modelo de familia por sobre otras uniones que actualmente son sucedáneas, sosteniendo una discriminación intolerable ${ }^{5}$. Salvo que la persona muerta sea la esposa del homicida, en Argentina da lo mismo matar a una mujer en un accidente de tránsito que en un episodio de violencia familiar, sin embargo, el código penal agrava la pena de homicidio en razón de la función social de la persona muerta cuando se mata a un policía o miembro de las fuerzas de seguri$\mathrm{dad}^{6}$. Si bien no se desconoce la discusión doctrinaria que se originó con esta medida

$5 \quad$ El modelo familiar de la legislación argentina, sea civil o penal, es abiertamente favorable a las uniones conyugales heterosexuales, sobre todo aquellas uniones que se formalizan en matrimonio. Esto puede explicar, junto a otros factores, que se haya demorado la legislación sobre matrimonio igualitario.

$6 \quad$ El artículo $80^{\circ}$ del CPA dice: "Se impondrá reclusión perpetua o prisión perpetua, pudiendo aplicarse lo dispuesto por el art. 52, al que matare... inc. $8^{\circ}$ : A un miembro de las fuerzas de seguridad públicas policiales o penitenciarias, por su función, cargo o condición". 
(Baigún y Zaffaroni, 2010), queda claro cuál es el bien jurídico protegido, cuánto le importa al Estado los policías y cuánto las mujeres.

Siguiendo con el análisis, es posible que la mujer con hijos menores de cinco años o personas bajo guarda cumpla condena domiciliaria. No soslayamos que la medida legislativa busca alternativas al encerramiento y advierte sobre las inhumanas condiciones de detención (Arduino y Sánchez, 2008; Centro de Estudios Legales y Sociales [CELS], 2008), sin embargo, consagra un estereotipo de mujer en torno al rol maternal y refuerza la idea de que están naturalmente preparadas para cuidar y criar a sus hijos/as pequeños/as. El artículo $10^{\circ}$ del CPA dice: "Podrán a criterio del juez competente, cumplir la pena de reclusión o prisión en detención domiciliaria: inc f) la madre de un niño menor de cinco años o de una persona con discapacidad a su cargo". Un hombre en iguales condiciones está excluido de la aplicación de esa norma. Si esta se mira desde la óptica de la protección de los derechos de los niños y niñas, el panorama para hijos/hijas de personas presas es abiertamente discriminador.

Aun podemos problematizar un poco más: si la abnegación de las mujeres por el cuidado de otras personas es una cualidad innata, ¿por qué el derecho les quita los/ as hijos/as a mujeres pobres, insanas o prostitutas? La respuesta es simple: como las tareas de cuidado de personas están ligadas a la manera en que una sociedad garantiza la reproducción social, el supuesto estado de naturaleza de las mujeres no es un buen argumento para sostener en estos casos? ${ }^{7}$. Por oposición a la "Mujer" están esas otras mujeres a quienes se estigmatiza.

Siguiendo con el desarrollo de las estrategias que despliega el derecho para crear subjetividades, encontramos el artículo $8^{\circ}$ del CPA que dice: "Los menores de edad y las mujeres sufrirán las condenas en establecimientos especiales". Esto tiene claras connotaciones de infantilización de las mujeres al ponerlas al mismo nivel que los/as niños/as.

En la relativamente reciente tipificación de la trata de personas para fines de explotación sexual, la ley deja intacta la red capitalista del negocio. Si bien la trama de la explotación de mujeres con fines sexuales es compleja, el derecho la reduce a la mínima expresión: identifica a la mujer rescatada y al facilitador, promotor o regente de la actividad. Suspicazmente, las prácticas sancionatorias del sistema penal excluyen toda la logística institucional involucrada, las redes de complicidad con los organismos de seguridad del Estado y la política, y el cliente sigue siendo ignoto e impune.

Continuando el recorrido acerca de cómo el derecho construye la idea de "mujer", hay un mito respecto de la delincuencia femenina, y es que como las mujeres están sujetas al control social informal dentro del ámbito privado de la familia, suele creerse

Similar posibilidad de cumplir condena domiciliaria tiene la mujer embarazada, conforme al artículo $10^{\circ}$, inciso e, del CPA. En este caso, el Estado reconoce la conveniencia del control patriarcal al interior de la familia sobre procesos supuestamente naturales y, a la vez, admite la impotencia de los servicios penitenciarios de apoyar, contener y acompañar a una embarazada en una experiencia vital que además es vista como el cumplimiento de un mandato social, esto es, que la función de las mujeres es tener hijos/as. 
que las mujeres no delinquen. En realidad estos supuestos se explican relacionando la criminalidad con los bienes jurídicos protegidos y con las ocasiones o contextos donde los delitos se consuman. Es posible que la delincuencia femenina sea distinta a la de los varones, pero otra cosa muy distinta es decir que las mujeres no delinquen.

Al respecto, costó mucho que los operadores del derecho penal entendieran que cuando la mujer mata a su agresor luego de años de violencia, no es con alevosía o ensañamiento, sino en legítima defensa (Di Corleto, 2006). La abnegación no debiera implicar la inmolación.

Desarrollo aparte merece el derecho de las mujeres sobre su propio cuerpo; este continúa cosificado en función del placer masculino y la reproducción. Los mandatos de una sexualidad heterosexual al servicio de la maternidad siguen siendo un valladar del patriarcado difícil de traspasar. Frente a este tema se discute sobre cuál resulta la mejor estrategia: una mayor regulación de las causales de aborto no punible o directamente la despenalización de esa conducta. La cuestión pasa por encontrar la postura que deje mayor margen de autonomía a las mujeres (Pitch, 2003), quienes se enfrentan a la disyuntiva de concurrir a los centros de salud para salvar su vida después de un aborto mal practicado o autoimputarse de un delito, mientras los varones no tienen ese dilema.

A veces la mano del derecho penal es larga, estigmatizadora, tan o más violenta que la misma violencia que denuncia, y otras veces es laxa, condescendiente y distraída. Temis ${ }^{8}$ suele andar a los tumbos porque tiene los ojos vendados.

No pretendemos hacer apología del derecho penal ni exigir más punición a cargo del Estado para solucionar el grave problema de la violencia hacia las mujeres en todas sus formas y modalidades, solo procuramos dar cuenta de una serie de inconsistencias del discurso jurídico en cuanto al género se refiere, y dejar planteado que, a veces, cuando el derecho dice "neutralidad", "objetividad", "imparcialidad", está queriendo decir "patriarcado".

\section{LA RESPUESTA PENAL A LOS PROBLEMAS DE LAS MUJERES}

Hay cierta fascinación acerca de lo que se puede esperar del derecho, más aún del derecho penal. Algunos grupos feministas han recomendado sancionar la violencia contra las mujeres en los códigos penales, tipificar los delitos de violación sexual y otros delitos sexuales dentro del matrimonio, tipificar como delito el acoso sexual y tipificar el femicidio (Equipo Latinoamericano de Justicia y Género [ELA], 2009).

8 Temis o Themis era la encarnación de la ley en la mitología antigua. En el transcurso de la historia ha sido representada como una mujer con los ojos vendados con una balanza en una mano y una espada o cornucopia en la otra, por eso se dice que la justicia es ciega. 
Muchas mujeres que sufren violencia familiar comienzan su peregrinaje con denuncias de violencia física, sicológica y sexual, hacen exposiciones, piden intervenciones policiales, etc. Los sistemas policial y judicial necesariamente dependen de una decisión política que advierta a los agresores que no se tolerará ni habrá impunidad para las conductas violentas.

Luego, cuando las denuncias han sido sistemáticamente desatendidas por las autoridades y se produce la muerte de una mujer, ocurre lo que era evitable. Por eso la tipificación y penalización de conductas violentas contra las mujeres, entre ellas el femicidio, no necesariamente evita la producción del hecho violento, pues no cumple una función preventiva ni la pena es disuasoria.

Teniendo en cuenta el desarrollo y evolución de la trama de violencia familiar, hay que contar con servicios y programas para actuar mucho antes del crimen. No es que las mujeres tengan derecho a no morir, sino que tienen derecho a vivir sin violencia, sin temor, intimidación y amenazas.

Hay que asegurar la efectividad de las leyes contra la violencia hacia las mujeres para que el recurso al derecho penal sea el mínimo posible, ante lo cual cobran relevancia las acciones para deslegitimar el uso de esta violencia.

Conocer la magnitud del fenómeno es el primer paso para exigir respuestas desde el derecho, pero alentar la criminalización de ciertas conductas tiene implicancias que no se pueden ocultar. No desconocemos la insuficiente e ineficaz protección que las mujeres obtienen del derecho penal. En este sentido, la Ley $N^{\circ} 26.485$ procura instalar la condena social a la violencia contra mujeres (Art. $9^{\circ}$, inc. q) y su deslegitimación social (Art. $7^{\circ}$, inc. b) por medio de sanciones de control social informal. Por ello, el hecho de que no se mencione en los fallos los antecedentes de violencia familiar cuando se investigaban los distintos delitos cometidos por parejas o exparejas de las mujeres víctimas muestra la desarticulación que hacen los operadores jurídicos. Los delitos son "un" hecho; la violencia hacia las mujeres es "un proceso" no exento de marchas y contramarchas ${ }^{9}$.

Tampoco desconocemos el potencial simbólico que tiene el uso de ciertos conceptos como femicidio o feminicidio ${ }^{10}$ en tanto ordenadores o clasificadores de la realidad. "Conceptualizar", como dice Amoròs (2008), permite politizar un problema. En ese sentido, el hecho de que los conceptos se familiaricen y extiendan entre los operadores jurídicos, que empiecen a tener presencia en la planificación de políticas

$9 \quad$ Tal vez por ello Larrauri (2008) se pregunta por qué las mujeres retiran las denuncian de violencia familiar; y responde: porque no se les puede pedir que confíen en un sistema que no las atiende.

10 Para la discusión sobre femicidio/feminicidio, véase Heinrich Böll Stiftung, 2010. Por otro lado, recientemente se trató el ¿asesinato? de dos turistas francesas en la provincia de Salta (Argentina). El diario Clarín abordó el tema en la sección "Policiales" en un claro encuadramiento reduccionista del fenómeno, invisibilizando el carácter social de la violencia hacia las mujeres (ver http://www.clarin.com/policiales/crimenes/stylecolorBF1424El-turistasfrancesasibrHablo-Cassandre-obsesion_0_570543127.html. consulta del 15 de marzo de 2012. 
públicas, seguramente dará visibilidad a un fenómeno que evidentemente requiere de acciones concretas.

Pero, aun así, a nuestro entender no hay punto de apoyo para pedir mayor control punitivo. En tal caso, el feminismo perdería su connotación libertaria y democrática: ¿cómo sostener la idea de una mayor criminalización si las cárceles están llenas de gente pobre, de inmigrantes y analfabetos/as? ¿Qué aportaría a las mujeres una mayor punición si lo que se requiere es visibilización, sensibilización y prevención de la violencia? ¿Por qué se apuesta a los supuestos beneficios del encerramiento? ¿Por qué pensar que más derecho penal redundará en una mayor autonomía y emancipación de las mujeres? ${ }^{11}$

\section{CONSIDERACIONES GENERALES SOBRE LA LEY $\mathbf{N}^{\circ} \mathbf{2 6 . 4 8 5}$ DE VIOLENCIA DE GÉNERO}

La Ley Nacional N²6.485, denominada "de Protección Integral para Prevenir, Sancionar y Erradicar la Violencia contra las Mujeres en los Ámbitos en que Desarrollen sus Relaciones Interpersonales", y el decreto presidencial N 1011/10 regulan el fenómeno de violencia contra las mujeres en Argentina, así como siguen vigentes en todo lo que no esté expresamente derogado la Ley Nacional 24.417 de Violencia Familiar y las leyes de violencia familiar o doméstica dictadas por las provincias ${ }^{12}$.

En cuanto al tema del presente artículo, es decir, la aplicación del derecho penal y el fenómeno de la violencia contra las mujeres, la Ley No 26.485 (Op. cit.) promueve y garantiza "el acceso a la justicia de las mujeres que padecen violencias" (Art. $2^{\circ}$, inc. f). Además, el Artículo $3^{\circ}$, inciso i, dispone la gratuidad del servicio de justicia, cuestión que se reitera como lineamiento de políticas estatales en el Artículo $10^{\circ}$, inciso c, y el Artículo $16^{\circ}$, inciso a.

Entre las acciones que deben llevar a cabo los poderes judiciales (nacional y provinciales) se encuentran la de "promover políticas para facilitar el acceso de las mujeres a la Justicia mediante la puesta en march a y el fortalecimiento de centros de información, asesoramiento jurídico y patrocinio jurídico gratuito" (Ibíd., Art. 11², parag. 5.1, inc. a).

11 Para dimensionar la complejidad de la relación entre derecho penal y feminismo, ver Maqueda, 2008; entrevista a Patsili Toledo Vazquez disponible en http://old.kaosenlared.net/noticia/patsili-toledo-vasquez-abogada-feministamujer-busca-proteccion-estado consulta del 15 de marzo de 2012 y entrevista a Íñigo Ortiz de Urbina Gimeno disponible en http://www.pagina12.com.ar/diario/principal/index-2011-03-08.htm/ consulta del 8 de marzo de 2011.

12 En atención a la estructura federal del Estado argentino, tanto el Parlamento Nacional como las legislaturas provinciales y de la Ciudad Autónoma de Buenos Aires tienen facultades legisferantes en el tema de la violencia hacia las mujeres. En el caso particular de la provincia de La Pampa, antes de la sanción de la Ley No 26.485 se encontraba vigente la Ley Provincial 1918 contra la Violencia Familiar y Escolar. Creemos que la Ley quedó derogada ante la sanción de la N²550, que adhiere a la 26.485 tanto en la parte sustantiva (derechos) como en la parte formal (procedimientos para hacer valer los derechos). La Ley tiene tres partes: la primera corresponde al derecho de fondo que sustancialmente recepta los principios del derecho internacional de los derechos humanos; la segunda es una regulación de las políticas públicas y la tercera ordena los aspectos formales. Es de orden público y de aplicación obligatoria en todo el territorio nacional, salvo en los aspectos procedimentales. 
La Ley Nacional No 26.485 protege a las mujeres en su integridad física, psicológica, sexual y económico-patrimonial (Ibíd., Art. $3^{\circ}$, inc. C), estableciendo tipos y modalidades de violencia. Entre aquellos, tenemos: violencia física, psicológica, sexual, económica y patrimonial y simbólica; mientras que las modalidades son: violencia doméstica, institucional, laboral, contra la libertad reproductiva, violencia obstétrica y mediática.

El principio de transversalidad contenido en el Artículo $7^{\circ}$ inc. d) prevé la acción conjunta con entidades de la sociedad civil (art. $7^{\circ}$ inc e) y art $9^{\circ}$ inc. c) y entre las distintas jurisdicciones y organismos del Estado, por medio de la autoridad de aplicación, que es el Consejo Nacional de la Mujer (Art. $8^{\circ}$ ). El principio señalado está emparentado con el trabajo interinstitucional e interdisciplinario que se menciona en varios artículos de la Ley mediante acciones de articulación, coordinación e intercambio. Este organismo debe

"Brindar capacitación permanente, formación y entrenamiento en la temática a los funcionarios públicos en el ámbito de la Justicia, las fuerzas policiales y de seguridad, y las Fuerzas Armadas, las que impartirán de manera integral y específica según cada área de actuación, a partir de un módulo básico respetando los principios consagrados en esta ley" (Ibid., Art. 9, inc. h).

En tanto, el inciso m) establece que deberá coordinar con el Poder Judicial los criterios para la selección de datos, modalidad de registro e indicadores para la confección de estadísticas, cuestión reiterada en el Artículo 11², parág. 5, incisos c) y e).

En Argentina no se construyen estadísticas criminales con perspectiva de género. El Estado no registra ni contabiliza los delitos contra mujeres en hechos de violencia doméstica, pese a que la Ley No 26.485 obliga al Consejo Nacional de la Mujer a:

"Desarrollar, promovery coordinar con las distintas jurisdicciones los criterios para la selección de datos, modalidad de registro e indicadores básicos desagregados-como mínimo-por edad, sexo, estado civil y profesión u ocupación de las partes, vínculo entre la mujeres que padece violencia y el hombre que la ejerce, naturaleza de los hechos, medidas adoptadas y sus resultados, y sanciones impuestas a la persona violenta" (Ibíd., Art. 9, inc. I).

Para dar cuenta de ese problema, el Estado toma como ciertos los datos de muertes de mujeres que recoge la Asociación Civil Casa del Encuentro mediante el minucioso trabajo de revisar las noticias periodísticas que son publicadas en los medios de prensa de la Argentina. Esta organización relevó 260 casos de muerte de mujeres en antecedentes de violencia familiar durante $2010^{13}$.

La omisión de recoger y procesar datos con enfoque de género y, en base a ello, formular políticas públicas no es casual, constituye un incumplimiento del Estado de

13 Ver edición impresa del diario La Arena del 20 de enero de 2011, páginas 8-9, y diario Página 12, versión electrónica, del día 8 de marzo de 2011. 
acuerdo con las pautas dadas por la Recomendación General N 19 de la ONU (ELA, Op. cit: 293). Hay también una manda legal a los poderes judiciales ${ }^{14}$ para la elaboración de estadísticas en el Artículo $37^{\circ}$ de la ley nacional No 26.485.

En cuanto a la formación de los operadores jurídicos, la ley alienta la conformación de espacios de formación específica para profesionales del derecho (art. 11 parag. 5.1 inc. b y g) tema que se condice con la previsión legal de promover la incorporación de la temática de la violencia contra las mujeres en las currículas terciarias y universitarias, tanto en el nivel de grado como de postgrado (Art. $11^{\circ}$, parag. 3, inc. d). Con esto, actualizamos lo dicho respecto de la obsolescencia del paradigma positivista en la socialización profesional de abogados/as, juristas y otros profesionales involucrados. La cuestión de la formación interdisciplinaria resulta muy importante, debido a que los/as abogados/as tienden a pensar las distintas ramas del derecho como compartimentos estancos y a despreocuparse por los aportes que pueden brindar otros saberes.

Por otro lado, la ley también hace hincapié en evitar la revictimización que sufren las mujeres en su paso por las instancias policiales, sanitarias y judiciales (Art. $11^{\circ}$, parag. 5.2; art. 16 inc. h) e incluso establece el derecho a oponerse a la realización de inspecciones sobre su cuerpo (Art. $16^{\circ}$, inc. j), prácticas muy habituales, sobre todo cuando se trata de investigar delitos contra la integridad sexual y que conllevan procesos de revictimización muy claros.

Sobre la elección de política criminal, la ley no crea un tipo penal específico de violencia contra las mujeres. El Artículo 41 dice: "en ningún caso las conductas, actos u omisiones previstas en la presente ley importarán la creación de nuevos tipos penales, ni la modificación o derogación de los vigentes" (Ley No 26.485, Op. cit.).

Coincidimos en que "criminalizar un problema, aislarlo, conceptualizarlo como delito, implica un fuerte reduccionismo social que sitúa el problema en un espacio, el jurídico, que es notoriamente insuficiente en este caso, por las implicancias que tiene en sí mismo (Balaguer, 2005: 159). De esta manera, la Ley No 26.485 reenvía los casos de violencia contra las mujeres, en general, y los de violencia doméstica, en particular, a la justicia civil o ante el fuero de familia a partir del Artículo $16^{\circ}$.

El procedimiento -es decir, la tercera parte- establecido por la ley presenta ciertas características con relación a los plazos perentorios, la amplitud de prueba, la celebración de audiencias con la presencia del juez, la asistencia gratuita y especializada para la víctima, etc. A nuestro criterio, y dada la formación de los operadores del derecho, sus prácticas y rutinas, la cuestión formal y todo lo referido a los procesos debió derivarse a los respectivos códigos que dictan las provincias y no quedar incluido con cuestiones de derecho sustancial (primera parte) ni con la agenda de políticas públicas (segunda parte).

14 Al respecto, ver Sánchez, 2008. 


\section{LA LEY DE VIOLENCIA DE GÉNERO Y EL DERECHO PENAL}

Desarrollaremos dos de los posibles inconvenientes en la aplicación de la Ley Nacional N²6.485 con relación a la normativa penal. El primero tiene que ver con la prohibición del uso de medios alternativos de resolución de conflictos ${ }^{15}$ y su relación con la suspensión del juicio a prueba; el segundo, con la aplicación del principio de oportunidad.

En primer término, la mencionada ley no admite el uso de medios alternativos de resolución de conflictos, más precisamente la mediación y la conciliación. El Artículo $28^{\circ}$ establece la celebración de una audiencia en presencia del juez (civil o de familia), en la que no se permite acudir a estas opciones.

El impedimento de utilizar la mediación o la conciliación de manera absoluta como lo dispone la ley, olvida que a la víctima de violencia hay que empoderarla (Art. $9^{\circ}$, inc. e). Puede ser que, cuando la mujer concurra a la audiencia, esté lo suficientemente fortalecida y pueda llevar a cabo una mediación o conciliación satisfactoria a sus intereses, máxime teniendo en cuenta que, según el Artículo $16^{\circ}$, incisos c) y d), debe ser oída personalmente por el juez y su opinión ser tenida en cuenta. Además, se permite que la mujer sea acompañada en los trámites por personas de su confianza.

Por otro lado, el procedimiento de la suspensión del juicio a prueba, previsto en el Artículo 76 bis del CPA, es un claro ejemplo de medida alternativa a la imposición de una pena privativa de la libertad. Consiste en un acuerdo que formulan el fiscal y el imputado, y elevan al juez para evitar el cumplimiento de la condena. El magistrado valora el ofrecimiento de indemnización del delincuente y no está obligado a escuchar la opinión de la víctima si decide decretar la suspensión del juicio. Este artículo señala:

"El juez decidirá sobre la razonabilidad del ofrecimiento en resolución fundada. La parte damnificada podrá aceptar o no la reparación ofrecida, y en este último caso, si la realización del juicio se suspendiere, tendrá habilitada la acción civil correspondiente" (Código Penal Argentino, 2008, Artículo 76 bis).

Puede darse el caso que la mujer víctima de violencia familiar lo sea simultáneamente de un delito, y que el tipo penal encuadre en la suspensión del juicio a prueba. En un proceso no podrá conciliar ni aceptar mediación, mientras que, en el otro, el uso de medios alternativos está a disposición de otros actores (fiscal, juez e imputado) y no hay obligación de tener en cuenta su opinión.

Por eso creemos que la Ley № 26.485 debió pronunciarse expresamente y dar un claro mensaje a los operadores jurídicos en cuanto al uso de este tipo de institutos cuando los antecedentes del delito tienen que ver con la violencia de género. El presupuesto

15 Respecto del uso de medios alternativos de resolución de conflictos en casos de violencia familiar, ver Arduino y Sánchez, 2008. Véase también Medina, 2009. 
de "razonabilidad del ofrecimiento" contenido en el Artículo 76 bis del CPA admite una casuística imposible de prever y deja un margen de poder amplísimo al juez, que quién sabe cómo ha de ser usado. Se dice que el problema no es que los jueces decidan de cierto modo, sino que lo hagan de cualquier manera (Gargarella, 2006).

El segundo problema apuntado está relacionado con la aplicación de la Ley No 26.485 y el principio de oportunidad. Este instituto trata de establecer reglas claras para prescindir de la acusación penal que lleva adelante el fiscal, en casos en los cuales ordinariamente debía acusarse por un aparente hecho delictivo. Este criterio implica una concepción utilitaria y realista sobre la legitimación de la acusación fiscal y el fundamento, la finalidad y el límite de la aplicación de las penas.

El hecho de que fiscales y jueces elegían y eligen qué casos investigar y cuáles archivar no es una práctica novedosa, no por lo menos en los sistemas judiciales argentinos. Es consecuencia de que el sistema penal es selectivo y la perspectiva de los operadores, clasista.

Desde la dogmática jurídica se justifica la aplicación del principio de oportunidad porque no incrimina la conducta cuando existen otros mecanismos de reacción social más eficaces, por ejemplo, cuando hay una solución conveniente para la víctima y menos perjudicial para el imputado. En segundo término, el instituto pretendería volver los ojos hacia la víctima, reapropiarle el conflicto y hacerla protagonista de su solución. Una tercera razón está basada en un argumento práctico, y es que la aplicación del principio de oportunidad se orienta también a descongestionar tribunales atiborrados de expedientes.

Entonces, vale preguntarse, ¿cuál va a ser la práctica de los operadores jurídicos cuando apliquen el principio de oportunidad?

Teniendo en cuenta que el sistema jurídico reproduce la jerarquización dicotómica de los valores femeninos y masculinos, tal vez se recurra al principio de oportunidad para casos de violencia contra las mujeres y, así, tener tiempo y recursos para atender otras causas más "importantes".

Con lo que venimos exponiendo, queremos resaltar que la aplicación del principio de oportunidad no necesariamente reapropia el conflicto que sufre la víctima, ya que en sede penal los protagonistas son el juez, el fiscal y el imputado, y en sede civil o del fuero de familia porque tiene vedadas alternativas que en algunos casos pueden ser convenientes.

Un argumento jurídico para sostener la compatibilización de la Ley No 26.485 con las prescripciones señaladas del ordenamiento penal, a falta de norma legal expresa, sería aplicar los principios de "ley posterior deroga la anterior"y"ley especial deroga la general". En el caso, la ley de violencia de género es posterior y especial respecto del Artículo 76 bis del CPA. 


\section{OBLIGACIONES DE LOS OPERADORES DEL DERECHO PENAL EN CASOS DE VIOLENCIA INTRAFAMILIAR}

En todo caso, y con lo discutible que pueda resultar lo que acabamos de decir, siendo la ley de orden público, consideramos que los operadores del derecho penal, más precisamente quienes lleven adelante la instrucción de delitos que afecten a mujeres en situaciones de violencia, están obligados a aplicar los Artículos $16^{\circ}$ y $36^{\circ}$ cuando se trata de violencia familiar, porque son disposiciones de carácter general.

A riesgo de ser extenuantes, pero a fines de ilustrar la idea, transcribimos el Artículo $16^{\circ}$ de la Ley № 26.485, que dice:

"Derechos y garantías mínimas de procedimientos judiciales y administrativos. Los organismos del Estado deberán garantizar a las mujeres, en cualquier procedimiento judicial o administrativo, además de los derechos reconocidos en la Constitución Nacional, los Tratados Internacionales de Derechos Humanos ratificados por la Nación Argentina, la presente ley y las leyes que en consecuencia se dicten los siguientes derechos y garantías:

a) a la gratuidad de las actuaciones judiciales y del patrocinio jurídico preferentemente especializado;

b) a obtener una respuesta oportuna y efectiva;

c) a ser oída personalmente por el juez y por la autoridad administrativa competente;

d) a que su opinión sea tenida en cuenta al momento de arribar a una decisión que la afecte;

e) a recibir protección judicial urgente y preventiva cuando se encuentren amenazados o vulnerados cualquiera de los derechos enunciados en el artículo $3^{\circ}$ de la presente ley; f) a la protección de su intimidad, garantizando la confidencialidad de las actuaciones; g) a participar del procedimiento recibiendo información sobre el estado de la causa; h) a recibir un trato humanizado, evitando la revictimización;

i) a la amplitud probatoria para acreditar los hechos denunciados, teniendo en cuenta las circunstancias especiales en las que se desarrollan los actos de violencia y quienes [sic] son sus naturales testigos;

j) a oponerse a la realización de inspecciones sobre su cuerpo por fuera del estricto marco de la orden judicial. En caso de consentirlas y en peritajes judiciales tiene derecho a ser acompañada por alguien de su confianza y a que sean realizados por personal profesional especializado y formado con perspectiva de género;

k) a contar con mecanismos eficientes para denunciar a los funcionarios por el incumplimiento de los plazos establecidos y demás irregularidades" (Ley 26.485, Op. cit., Art. 16, inc. a-k).

Por su parte, el Artículo $36^{\circ}$ prescribe lo siguiente:

"Obligaciones de los/as funcionarios/as. Los/as funcionarios/as policiales, judiciales, agentes sanitarios y cualquier otro/a funcionario/a público/a a quien acudan las mujeres afectadas, tienen la obligación de informar sobre:

a) Los derechos que la legislación le confiere a la mujer que padece violencia, y sobre los servicios gubernamentales disponibles para su atención;

b) Cómo y dónde conducirse para ser asistida en el proceso;

c) Cómo preservar las evidencias" (Ibíd., Art. 36, inc. a-c). 
Por más que estos artículos estén ubicados en la parte procedimental de la ley y que esta no crea nuevos tipos penales, sostenemos que los funcionarios públicos penales deben cumplir con estas obligaciones. Si bien entre los fallos hay sentencias que son anteriores a la vigencia de la Ley No 26.485, similar precepto contenía a ley provincial No 1918.

\section{PARADIGMA TEÓRICO DE LA LEY N² 26.485}

La ley se enmarca en un paradigma explicativo denominado modelo ecológico. La violencia familiar es el resultado de la confluencia de causales individuales, familiares, comunitarias y culturales. Los modelos de vinculación social y familiar se aprenden y se reproducen en discursos y prácticas, de allí que cobre especial relevancia el objetivo de remover estereotipos socioculturales que promueven y sostienen la desigualdad de género y las relaciones de poder sobre las mujeres (Art. $2^{\circ}$, inc. e). En esta misma línea, la ley sanciona la violencia simbólica como aquella que transmite o reproduce la dominación, desigualdad y discriminación (Art. 5, inc. 5) e incluye acciones concretas para democratizar las relaciones familiares (Art. 11 ${ }^{\circ}$, parag. 3.a).

Debido a que el fenómeno tiene un origen relacional, la ley procura evitar la judicialización si es posible realizar otro tipo de abordaje. Como último remedio remite a la intervención de la justicia civil o de los tribunales de familia, aun cuando por los mismos hechos intervenga la justicia penal.

La idea que subyace al modelo de abordaje es que algo hay que hacer con quien ejerce la violencia. Así, el Artículo $7^{\circ}$, inciso c), prevé la reeducación de quienes ejercen violencia, mientras, sobre las medidas preventivas urgentes, se establece que el juez o jueza podrá

\footnotetext{
"Proveer las medidas conducentes a brindar a quien padece o ejerce violencia, cuando asílo requieran, asistencia médica o psicológica, a través de los organismos públicos yorganizaciones de la sociedad civil con formación especializada en la prevención y atención de la violencia contra las mujeres" (Ibíd., Art. 26, inc. a.5).
}

También el Artículo 9, en su inciso p), postula la rehabilitación de hombres que ejercen violencia. No solo hay que empoderar a la víctima, hay que intervenir y trabajar con el entorno comunitario y social de todos los involucrados en prácticas violentas.

\section{LAS SENTENCIAS PENALES}

Hemos elegido cinco sentencias dictadas por las Cámaras Criminales de Santa Rosa (La Pampa, Argentina). Si bien algunas fueron dictadas con anterioridad a la vigencia de la Ley $N^{\circ} 26.485$, debieron cumplirse las prescripciones de la Ley No 1918 que reglamentaba en el plano provincial la violencia doméstica. El Artículo $4^{\circ}$ de esta última disponía que las acciones de dicha ley no se oponen a las civiles ni a las penales correspondientes, mientras que el Artículo $6^{\circ}$ obligaba a los funcionarios públicos a hacer las comunicaciones cuando por su desempeño supieran de casos de violencia 
familiar. Por lo tanto, si los jueces penales sentenciaban en causas de violencia familiar, estaban obligados a comunicar el caso al fuero civil o de la familia, bajo las prescripciones de la Ley No 1918 o, actualmente, por la obligación legal estatuida en la Ley $N^{0} 2550$, dato que no surge de las sentencias.

Entrando al análisis de las causas, en la N 11/2006 se investigó las lesiones recibidas por la exconcubina del imputado. No hubo acuerdo entre los operadores jurídicos en la calificación de los hechos. El juez de instrucción dijo que se trataba de lesiones graves con ensañamiento; el fiscal las calificó como gravísimas; el querellante particular (la víctima), como tentativa de homicidio con alevosía; la defensa del imputado -ejercida por una mujer abogada- las tipificó como lesiones graves y el tribunal sentenciante, integrado por tres jueces, finalmente condenó por lesiones gravísimas imponiendo seis años de prisión al agresor.

Sin embargo, y tratándose de un claro hecho de violencia doméstica cometido por la expareja de la mujer en su casa y supuestamente mientras discutían las cláusulas de un convenio de alimentos del hijo en común, no se mencionan en la sentencia los hechos de violencia padecidos por la mujer. No hay constancia en el fallo que la querellante particular (en este caso, la propia víctima, por medio del patrocinio de un abogado) fundara su pedido de tentativa de homicidio en los antecedentes violentos del exconviviente.

El fenómeno de la violencia doméstica que involucró a víctima y victimario quedó totalmente invisibilizado. Es difícil explicar la resolución desde lo estrictamente técnico y que, con los antecedentes relatados, la condena haya sido tan solo por lesiones gravísimas. Se comprobó que el imputado portaba un cuchillo con el que asestó ocho puñaladas a la víctima, además de provocarle una fractura en un brazo. Asimismo, quedó constancia de que la mujer había hecho catorce denuncias previas al evento que se investigó, así como también hubo trámites ante una defensoría civil en los que se ordenaba al hombre una prohibición de acercamiento.

Sostenemos que el fallo no consideró la intencionalidad del hecho y decidió por lesiones gravísimas. Como máximo, podemos acordar que una persona aseste una puñalada "sin querer", pero nunca ocho y que luego huya del lugar del hecho sin prestar ayuda a la víctima. Este caso ameritaba contemplar el dolo al cometer el delito, es decir, la intención de dañar.

Para fundar el fallo en lesiones gravísimas, el tribunal tuvo en cuenta la versión de los acontecimientos relatados por la víctima y que el ataque "se limitó a escasos minutos, sin que en el transcurso de la agresión se anunciara por parte de V... su intención de matarla". Suerte que el agresor fue rápido y callado pues, de lo contrario, hubiera dejado sin argumentos a los jueces.

Cuando la sentencia rescata que el imputado siempre mantuvo el control de su arma, por lo que, de haberlo querido, hubiera matado a la mujer, reafirma un estereotipo 
que se atribuye a los varones: ellos pueden/saben mantener el control de la situación. En la dicotomización de virtudes asignadas a mujeres y hombres, mencionada con anterioridad, estos son racionales. Como consecuencia, los magistrados concluyeron que el agresor, pudiendo matar, no quiso. Fruto de la perspectiva sexista, el tribunal no advirtió que el agresor en realidad no quiso controlar el cuchillo, pues el objetivo era poner a raya a su expareja. Hay una cosificación de la mujer, a quien se puede controlar y poner en su lugar como si fuera un objeto. La racionalidad y la capacidad de control que los jueces subrayaron no se corresponden con la irracionalidad del resultado final del evento.

Según el texto de la sentencia, el ciclo de violencia en esta expareja duró cinco años hasta que desencadenó en lesiones gravísimas, plazo más que suficiente para atender los reclamos de la mujer, quien ya había pedido ayuda. Aun así, tan naturalizada está la violencia que la propia víctima no consideró haber tenido una relación realmente violenta con el imputado hasta después del evento, cuando empezó a recibir ayuda profesional.

El rompecabezas de violencia vivida por la mujer no pudo ser rearmado por el tribunal para recrear un escenario real del problema y derivó en un fallo a todas luces sesgado e impregnado por una perspectiva patriarcal.

En otra causa, la N³7/2006, se investigó la tentativa de homicidio de la expareja del victimario. El hecho ocurrió en la vereda del comercio donde trabajaba la mujer víctima y fue cometido en presencia de ocasionales transeúntes, uno de los cuales logró evitar un peor desenlace al interferir con la agresión propinada por el hombre.

En este caso, salvo el defensor del imputado, que pidió se lo condenara por lesiones graves, los demás operadores (juez de instrucción, fiscal y querellante particular) coincidieron en que se trataba de homicidio en grado de tentativa. Así falló el Tribunal del Crimen, imponiendo una condena de siete años de prisión.

Si bien el relato de la sentencia hace mención a que las partes habían sido convivientes, los operadores nada dicen de la violencia y de la evolución cíclica de este fenómeno al no aceptar el imputado la ruptura de la relación sentimental.

A pesar de que en esta causa los peritos forenses informaron que las nueve heridas de arma blanca no pusieron en riesgo la vida de la víctima, la calificación del tribunal fue más rigurosa que en el caso anterior, en que efectivamente existió peligro de vida ${ }^{16}$.

16 Desconocemos las razones por las cuales los mismos jueces fundaron de manera tan disímil hechos relativamente semejantes en un plazo no mayor de cuatro meses, sin embargo, especulamos al respecto: un crimen se cometió dentro de una vivienda y otro en la vía pública. Aquí corresponde analizar más detalladamente en el curso de la investigación la incidencia de la categoría "público/privado" en la resolución de casos de violencia familiar. 
En la causa N 57/2006 se investigaba la comisión de lesiones graves en perjuicio de la concubina del agresor, quien, ante la negativa de mantener relaciones sexuales, fue golpeada en la cara, recibió rodillazos y fue lanzada contra la pared. A continuación el victimario se retiró del hogar, dejando a la mujer bajo la atención de la mucama.

El Código de Procedimiento Penal permite recurrir al Ilamado juicio abreviado, por el cual puede llegarse a un acuerdo con el fiscal si la pena privativa de libertad no supera los seis años. En este caso, la fiscal pidió la aplicación de una pena de dos años y seis meses, por lo que se recurrió al procedimiento mencionado. Si bien se requirió la opinión del querellante particular -es decir, de la víctima, por medio de su letrado-, tal opinión no es vinculante para el juez. El Artículo $406^{\circ}$ quáter del Código de Procedimiento Penal dispone:

"El Tribunal de juicio tomará conocimiento de visu del acusado, y lo escuchará si éste quiere hacer alguna manifestación. Si el Tribunal no rechaza la solicitud, argumentando la necesidad de un mejor conocimiento de los hechos o su discrepancia fundada en la calificación legal admitida, Ilamará a los autos ${ }^{17}$ para sentencia que deberá dictarse en un plazo máximo de quince días. Si hubiere querellante, previo a la adopción de cualquiera de estas decisiones, le recabará su opinión, la que no será vinculante".

No hay mayores datos acerca de los antecedentes de violencia en el relato de la sentencia, pareciera que el único episodio fuera el que se investigó. El derecho penal atomiza el conflicto y lo saca de contexto, resolviéndolo según el resultado. El hecho de que el agresor no tuviera antecedentes y que las lesiones no pusieron en riesgo la vida de la mujer hizo que el tribunal aceptara la propuesta efectuada.

La sexualización de la mujer no es un dato relevante para el tribunal. Los hombres están acostumbrados a hacer uso del cuerpo de las mujeres a discreción, entonces, cuando afrontan una negativa, por el motivo que sea, perciben cuestionada su masculinidad y recurren a la violencia. A un hombre no se le puede decir que no.

Casos como el reseñado, debido a la repercusión mediática que tienen, contribuyen a desmitificar una creencia muy arraigada: que la violencia ocurre en determinadas clases sociales, más precisamente, entre los pobres. Episodios como el investigado en esta causa dejan en claro que ello no es así, ya que el agresor era un comerciante, instruido (es decir, con un cierto nivel educativo), la pareja tenía al menos un automotor de importante valor y personal doméstico sin retiro, lo que denota un estatus social medio-alto.

Sin perjuicio de las críticas formuladas, a nuestro juicio, debe rescatarse la segunda parte del fallo, en la que se ordena al agresor hacer un tratamiento terapéutico en servicios de violencia familiar oficiales, "que permita modificar su personalidad respecto al conflicto de violencia que suscitara estas actuaciones". Esto es posible en juicios penales

17 En lenguaje jurídico, autos significa expediente o causa. 
cuando la condena es de cumplimiento condicional (Art. $27^{\circ}$ bis). Si hubiera sido de cumplimiento efectivo, la posibilidad de ordenar estas terapias no es viable.

Entre las sentencias seleccionadas, encontramos el fallo correspondiente a la causa N³8/2005, donde se condenó a un hombre por la promoción y facilitación de la prostitución de su pareja mayor de dieciocho años. Resaltamos que la mujer prostituida se hallaba desaparecida al momento del juicio y se investiga actualmente su desaparición.

La causa se inició por la denuncia que hizo la madre de la víctima. El juez de instrucción y el fiscal acordaron en la calificación del delito, mientras que la defensa del imputado, ejercida por una mujer, pidió la absolución o la aplicación de la pena mínima. De acuerdo con el Código Procesal Penal vigente en aquella fecha, a los familiares de la víctima desaparecida no se les permitió ser querellantes ${ }^{18}$.

El fallo relata pormenorizadamente la seguidilla de hechos violentos que padeció la víctima a manos del proxeneta. Este no solo negó el hecho, sino que atribuyó la prostitución de la víctima a su propia voluntad, la que ejercía aun antes de conocerla. Sin embargo, esto no es otra cosa que un mecanismo de neutralización de la conducta delictiva, ya que los testigos coinciden en la situación de terror y permanente intimidación que sufría la víctima, quien pedía que no denunciaran los hechos a la policía por miedo a las represalias.

Como ya dijimos, en este tipo de delitos contra la integridad sexual hay una connotación moral que muchas veces deriva en la indagación de la moral sexual de la víctima. En este fallo, el tribunal se detuvo en remarcar que la víctima no ejerció la prostitución sino hasta relacionarse con el victimario y que "se desenvolvía en el ámbito de una familia de buenas costumbres". Estas apreciaciones están fuera de lugar y corresponden a un razonamiento sexista de parte de los jueces: olvidan que debían investigar al imputado, no a su víctima.

Aun teniendo en cuenta la forma en que se cometió el delito y el estado de terror en que vivía la víctima, el tribunal impuso la pena mínima de cinco años prevista para el delito. Nos preguntamos si los jueces consideraron "la naturaleza de la acción y los medios empleados para ejecutarla, la extensión del daño y el peligro causados" (Código Penal Argentino, Op. cit., Artículo $41^{\circ}$ ) para establecer el monto de la pena. Aunque la condena fue de cumplimiento efectivo, e incluso con la vigencia de la Ley No 1918, los jueces penales no comunicaron el caso a la justicia del fuero de familia, que es la competente, ni ordenaron tratamiento terapéutico al delincuente ${ }^{19}$.

$\overline{18}$ La imposibilidad de que familiares de la víctima de promoción de la prostitución puedan ser querellantes marca nuevamente la atomización del conflicto. Pareciera que promover la prostitución fuera un hecho aislado, no un proceso que conlleva violencia física, sicológica y económica hacia la mujer prostituida. Para el procedimiento penal el problema no es social sino particularizado al caso concreto.

19 Resaltamos que el victimario de este caso, luego de la sentencia que comentamos, fue condenado en otras dos causas por violencia doméstica, lo que nos lleva a reafirmar la ineficacia del derecho penal para conjurar la violencia contra las mujeres. 
Por último, analizaremos la sentencia dictada en la causa 22/2010, una vez vigente la Ley Nacional No 26.485. En este caso, el juez de instrucción calificó los hechos como homicidio simple por parte del conviviente contra su pareja, agravado por el uso de arma de fuego en grado de tentativa en concurso material con el delito de tenencia ilegal de armas de fuego. La fiscal lo recalificó como "lesiones gravísimas culposas en concurso" y el defensor coincidió con la calificación menos rigurosa. Finalmente, el tribunal falló por lesiones graves culposas, un tipo penal aún menos gravoso para el imputado, con tres años de prisión, inhabilitación y multa.

El fallo destacó la contradicción de la mujer cuando declaró ante el juez de instrucción y ante el tribunal. En principio, la víctima había dicho que el imputado deliberadamente había querido matarla y que no era primera vez que estos eventos ocurrían. Posteriormente, sostuvo que el disparo fue accidental y que en realidad ella se quiso matar, lo que llevó al imputado a tomarle el arma, forcejear y provocar la detonación. Como la víctima se desdijo y el imputado en todo momento conservó la coherencia en el relato, los jueces interpretaron los hechos de la manera más favorable al hombre. El tribunal dice haber "percibido como verosímiles y sinceros" los dichos de la víctima, "acordes además con el resto del material probatorio desde un punto de vista lógico".

Si bien se le asigna una cierta irracionalidad al primer testimonio de la víctima, para interpretar los hechos en beneficio del imputado, el segundo testimonio de la mujer resulta acorde a las reglas de la lógica. Sin embargo, lo importante no solo es la construcción discursiva de la sentencia, sino la expropiación del conflicto a la víctima y cómo fue tratada. No hay constancia de que el sistema penal la haya contenido ni que alguien se preocupara por averiguar por qué cambió su versión de los acontecimientos. Simplemente no resultó relevante que la víctima se identificara con su victimario al punto de visitarlo reiteradamente mientras estuvo detenido ni que ejerciera la prostitución; tampoco si el proxeneta era su concubino.

Estas múltiples "pistas" omitidas no son casuales, son parte de las lógicas y prácticas de los operadores. Demuestran cómo se abordan los hechos de violencia familiar y cómo se desarticula y sesga la experiencia vital de las mujeres.

A pesar de que estaba vigente la Ley Provincial No 2.550, que adhiere a la Ley Nacional No 26.485, no hubo medidas de empoderamiento para la víctima ni tratamientos para el condenado. El incumplimiento claramente redunda en una violencia institucional del Poder Judicial hacia las víctimas, según el inciso b) del Artículo $6^{\circ}$ de la Ley № 26.485.

\section{COMENTARIOS FINALES}

El dictado de Ley No 26.485 sin duda representa un logro en la lucha de las mujeres por visibilizar la violencia que padecen en razón del género. Sus propuestas son un desafío y su plena implementación requiere de una cuota muy importante de voluntad política para concretar numerosos aspectos, entre ellos, dotar de presupuesto suficiente a los ambiciosos programas de la ley y de los que puedan ponerse en marcha 
desde la sociedad civil, en aras de cumplir con los postulados interinstitucionales e interdisciplinarios.

La ley debe ser considerada como un punto de partida, un puntapié inicial de nuevas reivindicaciones de las mujeres, pero, aunque necesaria, no es suficiente. En tal sentido, hay que remover obstáculos sumamente arraigados en la cultura patriarcal, en la que también están comprendidos los operadores del derecho.

Teniendo presente las numerosas inconsistencias que presenta la aplicación de la Ley No 26.485 con relación al derecho penal, urge una actividad creadora y comprometida de los operadores jurídicos, que busque soluciones y alternativas innovadoras en los intersticios del derecho. Asimismo, urge el establecimiento de alianzas estratégicas con los movimientos de mujeres, a fin de que los casos de violencia, en general, y familiar, en particular, no queden impunes.

Lo anterior puede verse en la aplicación de los medios alternativos de resolución de conflictos, medios previstos en la ley penal y prohibidos en sede civil. También en el caso de la aplicación de institutos como el juicio abreviado, con relación a los tratamientos que se implementan como accesorios de la condena, para que no sean obligatorios solo cuando esta se cumpla en libertad sino que se prevean además cuando la persona es condenada a cumplimiento efectivo. Esto tiene directa relación con el modelo de abordaje ecológico que fundamenta la ley y con la consideración de que el problema de la violencia de género es un problema social, lo que está previsto por los Artículos $7^{\circ}$ y $9^{\circ}$, incisos c) y p), respectivamente, y el Artículo 26․ parag. a.5). Las acciones concretas sobre víctimas y victimarios tienen que ser abordadas mediante intervenciones interdisciplinarias y visibilizadas en sus dimensiones personal, familiar, comunitaria y sociocultural, para así empoderar a las mujeres y rehabilitar a quienes las violentan.

Mientras los operadores jurídicos, socializados profesionalmente bajo el paradigma positivista, insistan en separar los hechos de violencia penalmente sancionados de sus antecedentes fácticos de violencia familiar, persistirán los discursos y prácticas sesgadas propios de un sistema patriarcal institucionalizado mediante el derecho penal que, como vimos, nunca favorece a las mujeres.

La casuística estudiada revela que tanto bajo la vigencia de la Ley No 1918 como actualmente con las Nos 2550 y 26485 se incumple con la obligación legal de compatibilizar los hechos que se investigan en sede penal con los que son objeto de tratamiento en el procedimiento civil o del fuero de familia, lo que refuerza la idea de que los operadores jurídicos atomizan el conflicto, desarticulan su complejidad y lo hacen aparecer como un problema individual. Lo que sucede es que se focalizan en el resultado (muerte, lesiones, violación) y no en el proceso de violencia de género que deviene en delito. La judicialización de la violencia hacia las mujeres no hace más que particularizar el problema bajo un modelo de abordaje a todas luces insatisfactorio, por ende, en una primera aproximación, podemos sostener que los principios y 
mecanismos previstos en las Leyes Nos 2550 y 26485 no se aplican y priman criterios punitivos que desconocen la especificidad del conflicto.

Debido a las características de la violencia hacia las mujeres, se requiere que los operadores jurídicos comprendan el ciclo de violencia, informen los derechos a las víctimas, modifiquen las prácticas discursivas, incorporen la perspectiva de género y utilicen el potencial simbólico y ejemplificador del derecho penal para enviar un claro mensaje a la sociedad, y a los violentos en particular, datos que no surgen de los documentos estudiados.

Es necesario tener presente que más derecho penal no siempre es lo mejor para las mujeres, al menos las sentencias analizadas muestran un deficitario abordaje del problema en su faz penal. Dar más poder punitivo al Estado es, en definitiva, consagrar más violencia institucionalizada. Nada garantiza que esa mayor rigurosidad del derecho penal sea mejor usada. Si se quiere deslegitimar el uso de la violencia en las relaciones interpersonales, no cabe pensar que el derecho penal lo logrará por sí solo.

Por otro lado, también es necesario visibilizar la violencia contra las mujeres como una forma de discriminación y una violación de los derechos humanos, la que afecta no ya solo su desarrollo personal, sino que es un problema macroestructural de seguridad ciudadana que involucra a las instituciones jurídicas, de la salud y de educación públicas.

Los reiterados incumplimientos del Estado -y la demora en ejecutar el programa político de la ley- no solo lo hacen responsable ante los organismos del derecho internacional público, sino que deviene en violencia institucional.

Advertimos precedentemente que el análisis teórico conceptual del fenómeno de la violencia familiar y de las sentencias escogidas no tenía pretensiones de representatividad. Por el contrario, desde lo teórico, se requiere consensuar significados y sentidos de numerosos conceptos incluidos en la ley y, desde lo empírico, resta indagar en las aplicaciones que se hagan de la ley y si los medios legislados logran la finalidad de sancionar, prevenir y erradicar la violencia de género. Aun con estas limitaciones, creemos haber aportado al análisis de casos concretos y contribuido al debate y conocimiento de una legislación novedosa y promisoria.

\section{BIBLIOGRAFÍA}

Amoròs, Celia (1990): "El feminismo: senda no transitada de la llustración", en Isegoría. Revista de Filosofía Moral y Política, N 1, pp. 151-160 [on line]. Disponible en: http://isegoria.revistas.csic.es/index.php/isegoria/article/view/383/384 [Recuperado el 15 de marzo de 2012].

(2008): "Conceptualizar es politizar", en Laurenzo, Patricia; Maqueda, María Luisa y Rubio, Ana (coords.): Género, violencia y derecho, pp. 3-13. Buenos Aires: Editores del Puerto. 
Arduino, Ileana y Sánchez, Luciana (2008): "Proceso penal acusatorio y derechos humanos de las mujeres", en Rodríguez, Marcela y Asensio, Raquel (comps.): Una agenda para la equidad de género en el sistema de justicia. Buenos Aires: Editores del Puerto.

Asúa Batarrita, Adela (2008): "El significado de la violencia sexual contra mujeres y la reformulación de la tutela penal en ese ámbito. Inercias jurisprudenciales", en Laurenzo, Patricia; Maqueda, María Luisa y Rubio, Ana (coords.): Género, violencia y derecho, pp. 101-137. Buenos Aires: Editores del Puerto.

Baigún, David y Zaffaroni, Eugenio (dirs.) (2010): Código Penaly normas complementarias. Análisis doctrinario y jurisprudencial. Tomo 3. Buenos Aires: Hammurabi.

Balaguer, María Luisa (2005): Mujer y Constitución: La construcción jurídica del género. Madrid: Editorial Cátedra.

CELS (2008): Derechos humanos en Argentina. Informe 2008. Buenos Aires: Siglo XXI Editores.

Código Penal de la República Argentina (2008). Buenos Aires: Errepar, ver http://bibliotecas. ucasal.net/opac_css/index.php?lvl=author_see\&id=3549

Código Procesal de la provincia de La Pampa (2005). Editorial Gramma, Santa Rosa, La Pampa.

Decreto No 1011/10, en http://www.iurislex.com.ar/2010/07/20/decreto-101110.html

Diario La Arena versión impresa del 20 de enero de 2011, pp. 8/9, Santa Rosa, La Pampa.

Diario Página 12 disponible, en http://www.pagina12.com.ar/diario/elpais/1-1636842011-03-08.htm/ consulta del 8 de marzo de 2011.

Diario Clarín http://www.clarin.com/policiales/crimenes/stylecolorBF1424El-turistasfrancesasibrHablo-Cassandre-obsesion_0_570543127.html consulta del 15 de marzo de 2012.

Di Corleto, Julieta (2006):"Mujeres que matan. Legítima defensa en el caso de mujeres golpeadas", en Revista de Derecho penal y procesal penal, pp. 860/870, Lexis Nexis № 5/2006, mayo, Buenos Aires.

"Feminicidio: Un fenómeno Global. De Lima a Madrid". Publicado por la Heinrich Böll Stiftung - Unión Europea, Bruselas. Impreso en Bélgica, abril 2010. Edición: Patricia Jiménez y Katherine Ronderos disponible en http://www.cawn.org/assets/ Feminicidio\%20de\%20Lima\%20a\%20Madrid.pdf consulta del 15 de marzo de 2012. 
Gargarella, Roberto (2006): "Protesta social y parcialidad judicial”, en Birgin, Haydeé y Kohen, Beatriz (comp.), Acceso a la justicia como garantía de igualdad. Instituciones, actores y experiencias comparadas, pp. 109-128, Edit. Biblos Buenos Aires.

ELA (2009): Informe sobre Género y Derechos Humanos. Vigencia y respeto de los derechos de las mujeres en Argentina (2005-2008). Equipo Latinoamericano de Justicia y Género, Editorial Biblos, Buenos Aires.

Lamas, Marta (2000): "Género, diferencias de sexo y diferencia sexual", en Alicia Ruiz (comp.), Identidad femenina y discurso jurídico, pp. 65-84, Editorial Biblos, Buenos Aires.

Larrauri, Elena (2008): Mujeres y Sistema Penal. Violencia Doméstica. Editorial B de f Montevideo-Buenos Aires.

Laurenzo Copello, Patricia et al. (2008) (coord): Género, violencia y derecho, Editores del Puerto, Buenos Aires.

Ley Nacional No 26485, Boletín Oficial, www.boletinoficial.gov.ar, 14/04/2009.

Ley Provincial No 1.918, http://std.saij.jus.gov.ar/cgi-bin7wwwgetdocweb?registro=LEYP ROV\&docid $=L E Y \%$, consulta del 3 de noviembre de 2011.

Ley Provincial No 2.550, Boletín Oficial del 29 de enero de 2010.

Maqueda Abreu, María Luisa (2008): “ ¿Es la estrategia penal una solución para la violencia contra las mujeres? Algunas respuestas desde el discurso crítico feminista", en Laurenzo Copello, Patricia et al. (coord): Género, violencia y derecho, pp. 291-330, Editores del Puerto, Buenos Aires.

Medina, Graciela (2009): “El valor de las decisiones judiciales para evitar la violencia contra la mujer. Jurisprudencia de la Corte Interamericana de Derechos Humanos y Argentina sobre derechos humanos de las mujeres", Revista de Derecho de Familia y de las Personas, sept. 2009, Lexis Nexis, Buenos Aires.

Ortiz de Urbina Gimeno, Íñigo (entrevista) disponible en http://wWw.pagina12.com.ar/ diario/principal/index-2011-03-08.htm/ consulta del 8 de marzo de 2011

Pitch, Tamar (2003): Responsabilidades Limitadas. Actores, Conflictos y Justicia Penal, Editorial Ad-Hoc, Buenos Aires.

Rodríguez, Marcela V. y Raquel Asencio (comp) (2008): Una agenda para la equidad de género en el sistema judicial, Editores del Puerto, CIEPP, Buenos Aires. 
Ruiz, Alicia (2000): "La construcción jurídica de la subjetividad no es ajena a las mujeres", en Birgin, Haydeé (comp), El Derecho en el Género y el Género en el Derecho, pp. 19-29, Editorial Biblos, Buenos Aires.

Toledo Vazquez, Patsili (entrevista), disponible en http://old.kaosenlared.net/noticia/ patsili-toledo-vasquez-abogada-feminista-mujer-busca-proteccion-estado, consulta del 15 de marzo de 2012.

Sánchez, Luciana (2008): "Información Judicial y Derechos Humanos de las mujeres", en Rodríguez, Marcela V. y Raquel Asencio (comp.), Una agenda para la equidad de género en el sistema judicial, pp. 29-57, Editores del Puerto, CIEPP, Buenos Aires.

Smart, Carol (2000): "La teoría feminista y el discurso jurídico", en Birgin Haydeé (comp.), El Derecho en el Género y en Género en el Derecho, pp. 31-71, Editorial Biblos, Buenos Aires. 